\title{
Stress, coping, and depression: Testing a new hypothesis in a prospectively studied general population sample of U.S.-born Whites and Blacks
}

\author{
K.M. Keyes*, David M. Barnes, L.M. Bates \\ Columbia University, Department of Epidemiology, 722 West 168th Street, Suite \#720E, NY 10032, USA
}

\section{A R T I C L E I N F O}

\section{Article history:}

Available online 17 December 2010

\section{Keywords:}

Race

Depression

Mental health

Alcohol

Obesity

Socioeconomic position

African Americans

USA

Stress

\begin{abstract}
A B S T R A C T
The scarcity of empirically supported explanations for the Black/White prevalence difference in depression in the U.S. is a conspicuous gap in the literature. Recent evidence suggests that the paradoxical observation of decreased risk of depression but elevated rates of physical illness among Blacks in the U.S. compared with Whites may be accounted for by the use of coping behaviors (e.g., alcohol and nicotine consumption, overeating) among Blacks exposed to high stress levels. Such coping behaviors may mitigate deleterious effects of stressful exposures on mental health while increasing the risk of physical ailments. The racial patterning in mental and physical health outcomes could therefore be explained by this mechanism if a) these behaviors were more prevalent among Blacks than Whites and/or b) the effect of these behavioral responses to stress was differential by race. The present study challenges this hypothesis using longitudinal, nationally-representative data with comprehensive DSM-IV diagnoses. Data are drawn from 34,653 individuals sampled in Waves 1 (2001-2002) and 2 (2004-2005) as part of the US National Epidemiologic Survey on Alcohol and Related Conditions. Results showed that a) Blacks were less likely to engage in alcohol or nicotine consumption at low, moderate, and high levels of stress compared to Whites, and $b$ ) there was a significant three-way interaction between race, stress, and coping behavior for BMI only $(F=2.11, \mathrm{df}=12, p=0.03)$, but, contrary to the hypothesis, elevated BMI was protective against depression in Blacks at low, not high, levels of stress. Further, engagement in unhealthy behaviors, especially at pathological levels, did not protect against depression in Blacks or in Whites. In sum, the impact of stress and coping processes on depression does not appear to operate differently in Blacks versus Whites. Further research testing innovative hypotheses that would explain the difference in Black/White depression prevalence is warranted.
\end{abstract}

(c) 2010 Elsevier Ltd. All rights reserved.

\section{Introduction}

Epidemiologic studies have consistently documented that Blacks living in the United States have higher rates of physical illness such as hypertension and diabetes, and higher rates of mortality, compared with non-Hispanic Whites controlling for indicators of socioeconomic position (SEP) (Heckler, 1985; McCord \& Freeman, 1990; Williams \& Jackson, 2005). Conversely, major psychiatric epidemiologic household surveys have reported that Blacks have equal or lower rates of most psychiatric disorders, including major depression (Breslau et al., 2006; Hasin et al., 2005; Kessler et al., 1994; Williams et al., 2007). These divergent patterns for mental and physical health outcomes have been termed a 'paradox' (Williams, 2001). Blacks in the U.S. face historic and contemporary institutionalized discrimination which exposes them to disadvantaged SEP, worse living

\footnotetext{
* Corresponding author. Tel.: +1 212543 5002; fax: +1 2125435913

E-mail address: kmk2104@columbia.edu (K.M. Keyes).
}

conditions, and greater stress and adversity due to marginalized social status (Kessler et al., 1999; Kreiger, 2000; Williams \& WilliamsMorris, 2000), all of which seemingly place Blacks at greater risk for depression compared with Whites (Dohrenwend, 2000). Indeed, among Blacks in the U.S., perception of discrimination and adversity due to race is associated with greater psychological distress and depressive symptoms (Kessler et al., 1999; Williams \& WilliamsMorris, 2000). However, absolute rates of depression remain lower among Blacks compared with Whites.

Many pathways have been posited to explain the elevated rates of physical health problems among Blacks in the U.S. compared with Whites. One well-studied mechanism is stress associated with disadvantaged social status. The physiologic responses to stress via allostatic load have been hypothesized to influence health by a process of 'wear and tear' whereby the body can no longer effectively regulate itself (McEwen, 2000, 2004). "Weathering" (Geronimus, 1994, 1996), which describes a process of accelerated aging as an effect of the cumulative experience of stress and adversity, has been 
hypothesized to explain why Blacks have lower birth weights as well as higher mortality at younger ages than Whites after controlling for SEP. Further, interpersonal discrimination appraised by the individual as negative can result in fear, anger, and denial, thereby inducing injurious physiologic responses in cardiovascular, endocrine, neurologic and immune systems (Krieger, 1990; Kreiger, 2000; Krieger \& Sidney, 1996). Adverse neighborhood conditions, to which Blacks have greater exposure than Whites, can influence health through inadequate access to social and health services, exposures to health hazards, and reduction in social cohesion and connectedness (Massey, 1985, 2004). Greater stress, worse bodily wear and tear, reduced access to medical services, and greater exposure to deleterious neighborhood conditions are all risk factors for depression (Leonard, 2000; McEwen, 2003; Stansfeld, 2005), and yet Blacks consistently generate estimates of depression below those of Whites; this poses a perplexing, unresolved issue for social and psychiatric epidemiology.

Two methodological hypotheses advanced to explain this mental/ physical health paradox posit that rates of depression among Blacks are underestimated in major psychiatric epidemiologic studies due to selection bias and measurement error. The selection bias hypothesis reflects the fact that all major psychiatric epidemiologic surveys conducted in the U.S. exclude institutionalized populations. Young Black men in the U.S. are overrepresented in prison and jail populations (Petit \& Western, 2004), where depression is more prevalent compared with household populations (Teplin, 1990; Teplin et al., 1996). Thus, the underestimation of depression prevalence in household samples could affect Blacks to a greater extent compared with Whites, though the effect of this bias would primarily be age- and gender-specific. The measurement error hypothesis suggests potential diagnostic bias in the major survey instruments used to capture depression. Given the same symptom presentation, Blacks interviewed by clinicians in unstructured or semi-structured formats are more likely to be diagnosed as having a disorder in the psychotic spectrum and Whites as having a disorder in the mood spectrum (Neighbors et al., 1999, 2003; Strakowski et al., 2003). Additionally, some argue that depression may manifest differently in Blacks compared with Whites, and current diagnostic nosology more appropriately captures depression in Whites compared with Blacks (Baker, 2001; Brown, 2003; Kleinman, 2004; Rogler, 1999). Available data suggest that while these hypotheses may explain some of the Black/White difference in depression, methodological issues cannot account for the all of the difference (Breslau et al., 2008; Williams et al., 2007). Thus, hypotheses exploring alternative mechanisms through which Blacks may have a lower prevalence of depression compared with Whites remain necessary.

In contrast to methodological hypotheses explaining the mental/ physical health 'paradox', a recently advanced alternative hypothesis is that the patterning in physical and mental health outcomes in Blacks versus Whites arises from mechanisms for coping with stressors that on average operate differently for Black and White Americans (Jackson \& Knight, 2006; Jackson et al., 2009). Jackson and colleagues have argued that Blacks in the U.S. face greater, and unique, stressors compared with Whites, and that strategies deployed to cope emotionally with this increased stress may protect mental health while having deleterious consequences for physical health. Recently, Jackson and colleagues reported that at high levels of stress, Blacks with elevated body mass index (BMI) and/or who smoke cigarettes and/or drink alcohol (collectively termed 'unhealthy behaviors' or 'UHBs' (Jackson et al., 2009)) were less likely than Blacks not engaging in these behaviors to develop depression, whereas the pattern trended in the opposite direction for Whites (Jackson et al., 2009). Further empirical support for this hypothesis was recently reported using data from the Baltimore Epidemiologic Catchment Area Study (Mezuk et al., 2010). Evidence indicates that UHBs can ameliorate immediate anxiety and depressive symptoms in response to stressful experiences by regulating corticotropin-releasing factor in the hypothalamic-pituitary-adrenocortical (HPA) axis (Benowitz, 1988; Dallman et al., 2003; Koob et al., 1998). However, long-term heavy alcohol consumption, smoking, and high BMI can lead to a cascade of physical health consequences. This hypothesis suggests that, in the context of chronic stress, Blacks' engagement in UHBs may serve to buffer the deleterious consequences of stress on depression through the HPA pathway, leading to a lower prevalence of depression but a greater prevalence of physical health problems than would have otherwise occurred. This hypothesis also suggests that the same processes operate differently or with different consequences in Whites. In the interest of brevity, we refer to these potentially differential patterns in the relationships between stress, coping, and depression between Blacks and Whites as "group-specific," meaning that they arise from the unequal distribution of exposures and coping resources engendered by a racialized environment, rather than differences embedded in the individual.

Differences in stress and coping processes between Blacks and Whites could account for the mental/physical health 'paradox' under two scenarios. (1) UHBs are indeed protective against depression, among both Blacks and Whites, but Blacks are much more likely to engage in them compared with Whites at a given level of stress. This is unlikely in light of previous epidemiologic evidence suggesting that a) substance disorders and obesity are comorbid with depression (Hasin et al., 2005; Kessler et al., 1997; Reiger et al., 1990) and b) Blacks are less likely than Whites to engage in alcohol and nicotine consumption (Grant et al., 2004; Hasin et al., 2007). However, patterns of comorbidity and Black/White differences in depression at all levels of stress have not been investigated systematically. (2) UHBs operate differentially by race, whereby they protect against depression to a greater extent among Blacks compared with Whites (either overall or variably by level of stress). This hypothesis is supported by data from the Americans' Changing Lives Survey (Jackson et al., 2009) and the Baltimore Epidemiologic Catchment Area Study (Mezuk et al., 2010), as described above.

We propose to comprehensively investigate each of the above scenarios in a large nationally-representative prospective study of U.S. adults. The present study is intended to both replicate and extend the analyses presented in Jackson et al. (2009) to provide a comprehensive test of the underlying theory. Using the National Epidemiologic Survey on Alcohol and Related Conditions (NESARC) we accomplish five main aims. First, we construct as exact a replication as possible of Jackson et al. (2009) in order to provide a baseline for comparison and from which to broaden the analyses. The remaining four aims systematically test the theory underlying the two scenarios outlined above. We examine whether alcohol consumption, nicotine consumption, and body mass index (as a proxy for overeating, consistent with Jackson et al. (2009)) are prospectively protective against depression; we examine whether Blacks engage in more of these behaviors than Whites at low, moderate, and/or high levels of stress; and we test the hypothesis that Blacks exposed to high levels of stress are protected against depression if engaged in UHBs at the time of the stressors and, simultaneously, that Whites are not similarly conferred such protection from these behaviors. Finally, the hypothesis outlined by Jackson et al. (2009) suggests that the stress exposure of Blacks is qualitatively different compared to that of Whites. The NESARC data allows us to examine a measure of perceived racial discrimination in order to test whether Blacks who report high levels of discrimination and engage in UHBs have less depression than Blacks who report high levels of discrimination and do not engage in UHBs.

The data used in the present study have distinct advantages over those in Jackson et al. (2009): namely a larger sample size, DSM-IV diagnoses of major depression at two time points, DSM-IV diagnoses 
of nicotine dependence and alcohol use disorders, and comprehensive measures of nicotine, alcohol consumption, and stressful life events. Extending the analyses of Jackson et al. (2009) to include pathological alcohol and nicotine consumption is important in testing the hypothesis, as high and chronic levels of nicotine and alcohol use are behaviors most associated with poor physical health outcomes; if the Black/White "paradox" can be attributed to discrepant mental and physical health consequences of unhealthy behaviors, the nature and degree of engagement in those behaviors most implicated in poor somatic health should be considered.

\section{Methods}

Sample

Data are drawn from the National Epidemiologic Survey on Alcohol and Related Conditions (NESARC), a two-wave longitudinal survey of adults in the United States residing in households and group quarters. Wave 1 was conducted in 2001-2002 $(N=43,093)$; young adults, Hispanics and Blacks were oversampled, with an overall response rate of $81 \%$. Respondents were re-interviewed for Wave 2 approximately three years after Wave 1, with 34,653 (80.4\%) successfully re-interviewed. More information on the study methods is found elsewhere (Grant et al., 2009). The research protocol, including written informed consent procedures, received full ethical review and approval from the U.S. Census Bureau and the U.S. Office of Management and Budget.

\section{Measures}

All measures were assessed using the Alcohol Use Disorder and Associated Disabilities Interview Schedule-DSM-IV Version (AUDADIS-IV). We used measures of race/ethnicity, UHBs, and stressful life events ascertained at Wave 1 and measures of the outcomes, major depression and physical illness, from Wave 2. This design established the temporality of the exposures as occurring prior to the outcome; we controlled for major depression at Wave 1 in all analyses for which depression at Wave 2 was an outcome to further establish temporal sequence.

\section{Race/ethnicity}

We included self-identified non-Hispanic Whites $(N=19,216)$ and non-Hispanic Blacks $(N=6065)$ who reported being born in the U.S. Foreign-born Blacks $(N=664)$ and Whites $(N=1264)$ were excluded from the present analysis because patterns of substance use, depression and stressful life events differ between foreign- and non-foreign born individuals.

\section{'Unhealthy behaviors' (UHBs)}

We considered three types of 'UHBs': alcohol consumption, nicotine consumption, and body mass index (BMI). While a compelling argument can be made regarding the validity of terming alcohol consumption, nicotine consumption, and BMI collectively as 'UHBs' (e.g., moderate consumption of alcohol may be cardioprotective (Klatsky, 2009)), we have used this terminology to remain consistent with the prior empirical support for the hypothesis we are testing (Jackson et al., 2009). For our replication analysis, we use definitions exactly consistent with Jackson et al. (2009), namely a UHB count measure (0-3) indicating if the individual ever consumed at least one alcoholic beverage in their lifetime, ever smoked at least $100+$ cigarettes in their lifetime, and whether they currently have a BMI $\geq 30$. For our extended test of the overall theory, we used the following definitions:

Alcohol consumption in the past 12-months at Wave 1 was operationalized as a three-level variable: no consumption $(N=2293)$; non-pathological consumption (i.e., any level of consumption but no alcohol abuse/dependence diagnosis) at levels less than weekly binge ( $>4$ drinks for men or $>3$ drinks per women on at least one occasion in the past year) $(N=13,765)$; and DSM-IV alcohol abuse/ dependence or at least weekly binge drinking $(N=8593)$. Measurement of alcohol consumption and related diagnoses is a particular strength of the AUDADIS-IV instrument; diagnoses are made based on assessment of over 40 symptom items, and the excellent reliability and validity of alcohol diagnoses in the AUDADIS-IV have been extensively documented both in the United States and internationally (see Hasin et al., 2007). Limited differential item functioning by race/ethnicity has been noted for alcohol disorder criteria in Item Response Theory analysis (Saha et al., 2006).

Nicotine consumption in the past 12-months at Wave 1 was operationalized as a three-level variable: no nicotine use $(N=18,601)$; non-pathological use (any level of use but no DSM-IV-defined nicotine dependence diagnosis) $(N=3358)$; and DSM-IV nicotine dependence $(N=3313)$. The good reliability and validity of nicotine dependence in the AUDADIS-IV have been well-documented (Grant et al., 2004). Limited differential item functioning by race/ethnicity has been noted for nicotine dependence criteria in Item Response Theory analysis (Saha et al., 2010).

Unhealthy eating in the past 12-months at Wave 1 was operationalized using current BMI based on respondent's self-reported height and weight. BMI is an imperfect proxy for unhealthy eating; BMI is known to be determined by more than simply caloric intake, including exercise patterns and genetic vulnerability (Hetherington \& Cecil, 2010). However, empirical studies have documented a robust correlation between unhealthy eating and BMI (e.g., Haimoto et al., 2008; Kent \& Worsley, 2009). Three categories were created: BMI $<25(N=10,252)$, BMI greater than or equal to 25 but less than $35(N=12,615)$, and BMI $\geq 35(N=2414)$. While conventional cut-points define overweight as BMI between 25 and $<30$ and obese as $\geq 30$ (Centers for Disease Control and Prevention, 2010), we chose more conservative cut-points due to known error in the measurement of BMI (Rothman, 2008), often overestimating an individual's true body size.

UHB count. The three measures described above were combined to create an overall measure of UHBs, comparable to that in Jackson et al. (2009). Respondents were given a score of 0 for the least severe level of each behavior (i.e., no alcohol consumption, no nicotine consumption, or BMI $<25$ ), one point for the moderate level, and two points for the most severe level (i.e., DSM-IV alcohol abuse/dependence or at least weekly binge drinking, DSM-IV nicotine dependence, or BMI $\geq 35$ ) within each unhealthy behavior category. Based on this summary score, we created a three-level variable indicating no unhealthy behaviors (count was equal to zero) $(N=2539)$, low levels of unhealthy behavior (count was 1,2 , or 3$)(N=20,077)$, and high levels of unhealthy behaviors (count of 4 or more) $(N=2656)$.

\section{Stressful life events in the past 12-months}

Twelve stressful life events were assessed at Wave 1 using a checklist with dichotomous response options: family member or close friend had a serious illness (38.4\%), family member or close friend died (32.1\%), respondent changed jobs/job responsibilities/ work hours $(23.8 \%)$, moved or someone new came to live with respondent (15.8\%), major financial crisis/unable to pay bills/bankruptcy (10.6\%), trouble with a boss or co-worker (8.7\%), unemployed and looking for work $>1$ month (7.7\%), respondent or family member was the victim of a crime (6.7\%), fired or laid off (5.9\%), problems with neighbor/friend/relative (5.8\%), separated/divorced/broke up (5.4\%), and respondent or a family member had trouble with police/got arrested/sent to jail (5.1\%).

Fig. 1 shows the relationship between number of past-year stressful life events, race, and depression. As shown, the number of 


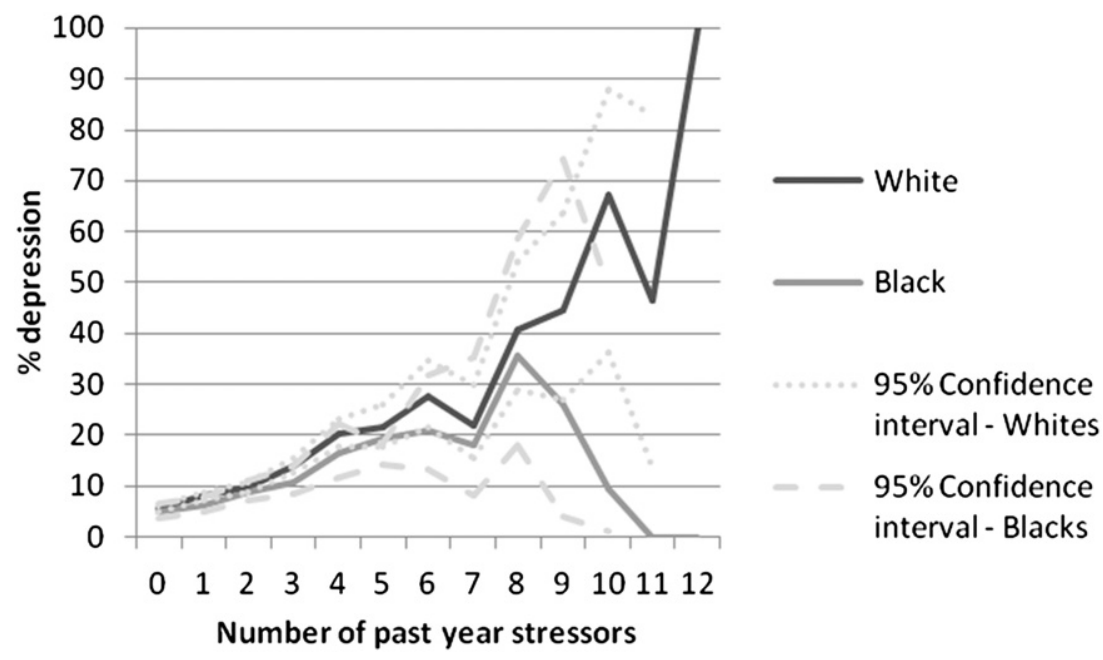

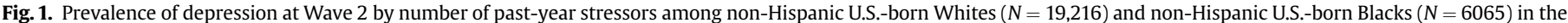
general population.

stressful life events at Wave 1 was not linearly related to depression at Wave 2 among Blacks, though the difference in prevalence between Blacks and Whites was not statistically significantly different at any level of stressful life events save for among those with one stressful life event $(p=0.04)$. Also shown in Fig. 1, the confidence intervals for the proportions substantially overlap, indicative of the small sample sizes among those with high levels of stress. Therefore, we created a categorical measure of the number of stressful life events reported by the respondent. We extensively evaluated the appropriate threshold for 'high stress', and found that the direction and magnitude of the results were not dependent on the upper cutpoint used. We also evaluated whether the data would fit a quadratic term for past-year stressful life events; the results did not change when a quadratic term was used. Therefore, to maximize statistical power and to provide the best fit to these data, we used the following cutpoints: no stressful life events in the past year $(N=7274)$, one or two stressful life events $(N=11,832)$, and three or more $(N=6175)$. Finer categorizations could not be utilized due to the minimum cell sizes required to conduct large-sample statistics.

\section{Perceived discrimination}

Respondents self-reporting Black race were asked at the Wave 2 interview, "How often have you experienced discrimination, been prevented from doing something, or been hassled or made to feel inferior in any of the following situations because of your race?" The frequencies of seven discrimination experiences in the past 12-months were assessed (e.g., obtaining health care or health insurance coverage, obtaining a job or while on the job, or being called a racist name) (Krieger et al., 2005). The scale showed good internal consistency reliability $(\alpha=0.76)$ (Ruan et al., 2008). Responses were summed and a three-level variable was created indicating: no discriminatory experiences reported $(N=3708)$, a low level of discriminatory experiences (more than zero but less than the 75th percentile on the scale, $N=1753$ ), and a high level of discriminatory experiences (75th percentile or greater, $N=604$ ).

Major depressive episode (MDE)

The good reliability and validity of DSM-IV major depression diagnosis in the AUDADIS-IV have been well-documented (Hasin et al., 2005). At Wave 1, major depression in the past 12-months or prior to the past 12-months was assessed; we combined these timeframes to create a W1 lifetime depression diagnosis, and used this variable as a control in all analyses predicting major depression at Wave 2. At Wave 2, major depression was assessed in the past 12-months, and since the last interview but prior to the past 12-months. We combined these times frames to create a W2 depression diagnosis.

\section{Physical illness}

We examined Black/White differences in fourteen physical illnesses (e.g., arteriosclerosis, hypertension, diabetes, heart attack, high cholesterol, ulcer) assessed at Wave 2. Physical illness status was based on respondent self-report of a physician diagnosis.

\section{Control variables}

In all analyses we also controlled for age, sex, past-year personal income, education, and region of residence as assessed at Wave 1. We also controlled for major depression at prior to the past year or the past-year Wave 1; Blacks had a lower prevalence of past year $(\mathrm{OR}=0.80,95 \%$ C.I. $0.66-0.96)$ and lifetime depression $(\mathrm{OR}=0.56$, 95\% C.I. 0.49-0.64) at Wave 1.

\section{Statistical analysis}

Prevalence estimates by race, stressful life events, and UHBs were generated using cross-tabulations. Odds ratios and 95\% confidence intervals were generated using logistic regression. All interaction tests are on the multiplicative scale. All analyses were conducted using SUDAAN software to adjust standard errors for the non-random probability of selection into the sample. All prevalence estimates and odds ratios are sample weighted to be representative of the U.S. population based on the year 2000 census.

\section{Results}

\section{Overall Black/White differences in the NESARC data}

Consistent with prior literature, Blacks were less likely to have Wave 2 major depression ( $\mathrm{OR}=0.80,95 \%$ C.I. 0.70-0.91) and more likely to have a Wave 2 physical illness ( OR $=1.20,95 \%$ C.I. $1.08-1.35$ ) compared with Whites (data not shown).

Results of the Jackson et al. (2009) replication attempt

Our findings did not replicate those of Jackson et al. (2009). Fig. 2a and $b$ show the predicted probability of depression based on the 

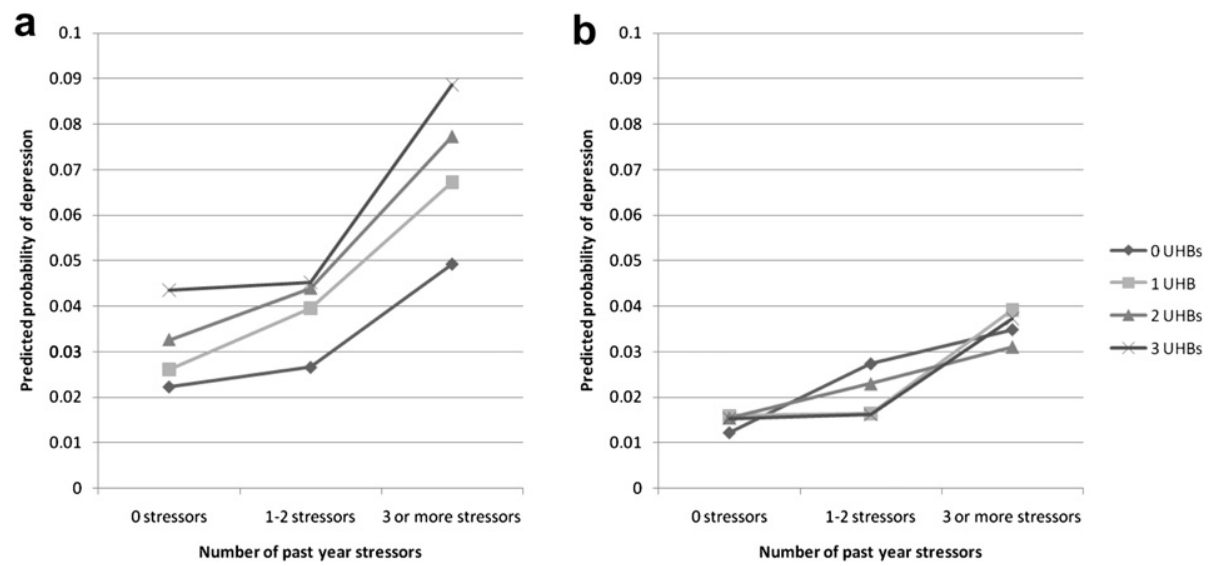

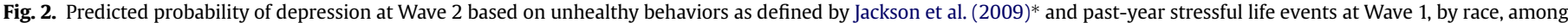

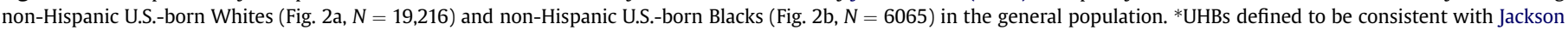
et al. (2009): any consumption of at least one alcoholic beverage in lifetime, any consumption of $100+$ cigarettes in lifetime, and/or current BMI $\geq 30$.

results of a logistic regression model categorizing UHB consumption (any lifetime smoking, any lifetime drinking, and/or current obesity) and past-year stressful life events, and controlling for age, sex, pastyear personal income, education, region of residence, and major depression at Wave 1 . Among Whites, the figures indicate a higher predicted probability of depression with each increasing level of UHB consumption and each increasing level of stressful life events. Among Blacks, the pattern is less consistent, but no evidence emerges suggesting that those who engage in more UHB consumption have less depression. There were no significant interactions between stressful life events and UHBs predicting depression among Blacks $(F=1.20, \mathrm{df}=6, p=0.32)$ or Whites $(F=0.43, \mathrm{df}=6, p=0.86)$, and no significant three-way interaction between stressful life events, UHBs, and race ( $F=1.05, \mathrm{df}=17, p=0.42)$.

As part of our replication attempt, we also conducted an analysis with a mean centered, continuous stress variable in order to more closely approximate Jackson et al. (2009) and Mezuk et al. (2010), despite the evident violation of the linearity assumption among Blacks (shown in Fig. 1). Among Blacks at high levels of meancentered stress, those with 0 UHBs have a higher predicted probability of depression compared to those with $1 \mathrm{UHB}$, and those with 1 UHB have a higher predicted probability of depression compared to those with 2 or 3 UHBs (consistent with Jackson et al. (2009) and Mezuk et al. (2010)). The same pattern is not evident among Whites (results not shown). However, this result arises entirely from the misspecification of the regression model by entering stress as a continuous variable among Blacks. Further, none of the interactions were significant when using the mean centered, continuous stress variable (interaction of stress and UHBs among Blacks: $F=0.89$, $\mathrm{df}=3, p=0.45$; interaction of stress and UHBs among Whites: $F=1.46, \mathrm{df}=3, p=0.23$; three-way interaction of stress, UHBs, and race: $F=1.37, \mathrm{df}=7, p=0.23$ ).

\section{Results of the extended test of the Jackson et al hypothesis}

Are UHBs protective against depression and is stress associated with more depression? We found that Wave 1 UHBs, at any level, are not protective against Wave 2 depression. Stress, however, is prospectively predictive of Wave 2 depression. Table 1 shows the odds of Wave 2 depression given Wave 1 UHBs among the whole sample, and for Blacks and Whites separately. Among Whites, greater Wave 1 alcohol, nicotine, BMI severity, and overall UHB score predicted higher odds of depression at Wave 2. Among Blacks, no significant odds ratios were observed for the relation between Wave 1 UHBs and Wave 2 depression. However, all four odds ratios for the highest UHB category were in the direction consistent with high levels of UHB predicting greater odds of depression. Among both Whites and Blacks, more stressful life events at Wave 1 predicted greater odds of depression at Wave 2 (see Table 1 ).

Do Blacks report higher levels of UHBs? Blacks had lower odds of Wave 1 alcohol consumption, nicotine consumption, and any UHBs compared with Whites, but a higher proportion of Blacks were in high Wave 1 BMI categories compared with Whites. This finding held in every level of Wave 1 stressful life events (see Table 2) save the lowest level. Among those with no stressful life events, there was no significant relationship between UHBs and race. The magnitude and strength of the relationship between UHB and race increased with each level of stressful life event category.

Do UHBs have a differential effect on depression among Blacks and Whites at certain stress levels? Little support was found for the hypothesis that UHBs have a differential effect on Blacks and Whites at high levels of stress. We examined whether the effect of Wave 1 UHBs on Wave 2 depression differed by race and Wave 1 stressful life event status (Table 3 ). Results indicated that a low level of unhealthy behaviors is protective against depression in Blacks ( $\mathrm{OR}=0.06,95 \%$ C.I. $0.01-0.24$ ) but not Whites ( $\mathrm{OR}=2.14$, 95\% C.I. 0.71-6.48) among those at low levels of stress. However, the three-way interaction test was not significant, limiting the conclusions that can be drawn from this association. We did find a significant three-way interaction between race, Wave 1 stress, and Wave $1 \mathrm{BMI}(F=2.11, \mathrm{df}=12, p=0.03)$. Based on the patterns of odds ratios shown in Table 3, we conclude that there is evidence to suggest a protective effect of Wave 1 BMI 25-34 on Wave 2 depression in Blacks but not Whites, but only at very low levels of stress.

We also examined these patterns by sex (results not shown). UHBs significantly interacted with race among men only $(F=6.07$, df $=2, p=0.004$ ), whereby Black men reporting a low level of unhealthy behaviors had significantly lower odds of depression compared to White men (OR $=0.06,95 \%$ C.I. 0.01-0.24). Similar to the aggregated analysis, a three-way interaction between Wave 1 BMI, race, and Wave 1 stress was statistically significant in men $(F=2.28, \mathrm{df}=12, p=0.02)$. This interaction was significant at the trend level among women $(F=1.7, \mathrm{df}=12, p=0.09)$.

Are UHBs protective against depression among Blacks reporting more race-specific stress? Wave 1 UHBs did not moderate the effect of perceived discrimination reported at Wave 2 among Blacks. The observed prevalence of Wave 2 depression by UHB consumption and discrimination experiences is shown in Fig. 3. In unadjusted analyses, Wave 1 non-pathological nicotine use was associated 
Table 1

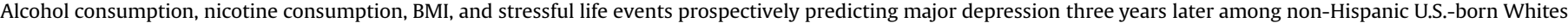
$(N=19,216)$ and non-Hispanic U.S-born Blacks $(N=6065)$.

\begin{tabular}{|c|c|c|c|c|c|c|c|c|c|}
\hline & \multicolumn{3}{|c|}{ All $(N=25281)$} & \multicolumn{3}{|c|}{ Whites $(N=19216)$} & \multicolumn{3}{|c|}{ Blacks $(N=6065)$} \\
\hline & $N$ & $\%$ & AOR (95\% C.I.) & $N$ & $\%$ & AOR (95\% C.I.) & $N$ & $\%$ & AOR (95\% C.I.) \\
\hline \multicolumn{10}{|l|}{ Alcohol consumption } \\
\hline $\begin{array}{l}\text { Alcohol abuse/dependence or at least } \\
\text { weekly binge drinking }\end{array}$ & 2923 & 11.89 & $1.31(1.10-1.57)$ & 2361 & 12.06 & $1.33(1.10-1.61)$ & 562 & 10.54 & $1.20(0.77-1.87)$ \\
\hline Non-pathological drinking & 13765 & 9.79 & $1.01(0.89-1.13)$ & 11192 & 9.90 & $1.02(0.90-1.16)$ & 2573 & 8.74 & $0.87(0.67-1.14)$ \\
\hline Abstention from alcohol & 8593 & 9.64 & 1.00 & 5663 & 9.63 & 1.00 & 2930 & 9.68 & 1.00 \\
\hline \multicolumn{10}{|l|}{ Nicotine use } \\
\hline Nicotine dependence & 3313 & 17.43 & $1.76(1.52-2.03)$ & 2689 & 17.88 & $1.80(1.54-2.11)$ & 624 & 13.10 & $1.29(0.90-1.85)$ \\
\hline Non-pathological nicotine use & 3358 & 9.12 & $1.06(0.91-1.24)$ & 2526 & 9.26 & $1.07(0.90-1.28)$ & 832 & 8.23 & $0.96(0.61-1.50)$ \\
\hline No nicotine use & 18601 & 8.78 & 1.00 & 13995 & 8.73 & 1.00 & 4606 & 9.09 & 1.00 \\
\hline \multicolumn{10}{|l|}{ BMI } \\
\hline$\geq 35$ & 2414 & 14.14 & $1.44(1.22-1.70)$ & 1478 & 14.66 & $1.52(1.26-1.82)$ & 936 & 12.25 & $1.14(0.80-1.62)$ \\
\hline$>25-<35$ & 12615 & 9.38 & $1.16(1.03-1.29)$ & 9349 & 9.54 & $1.19(1.05-1.34)$ & 3266 & 8.41 & $0.94(0.73-1.23)$ \\
\hline$\leq 25$ & 10252 & 9.89 & 1.00 & 8389 & 9.92 & 1.00 & 1863 & 9.69 & 1.00 \\
\hline \multicolumn{10}{|l|}{ Count of unhealthy behaviors } \\
\hline Four or more & 2539 & 14.97 & $1.96(1.56-2.48)$ & 1970 & 15.51 & $2.12(1.64-2.73)$ & 569 & 11.09 & $1.16(0.66-2.02)$ \\
\hline One to three & 20077 & 9.62 & $1.28(1.06-1.55)$ & 15337 & 9.69 & $1.34(1.09-1.65)$ & 4740 & 9.18 & $1.03(0.68-1.56)$ \\
\hline None & 2656 & 7.81 & 1.00 & 1903 & 7.55 & 1.00 & 753 & 9.19 & 1.00 \\
\hline \multicolumn{10}{|l|}{ Past 12-month stressful life events } \\
\hline Three or more & 6175 & 18.07 & $2.59(2.22-3.03)$ & 4427 & 18.59 & $2.64(2.23-3.13)$ & 1748 & 15.43 & $2.41(1.64-3.53)$ \\
\hline One or two & 11832 & 8.68 & $1.39(1.20-1.62)$ & 9046 & 8.83 & $1.40(1.19-1.65)$ & 2786 & 7.58 & $1.36(0.94-1.98)$ \\
\hline None & 7274 & 5.48 & 1.00 & 5743 & 5.55 & 1.00 & 1531 & 4.89 & 1.00 \\
\hline
\end{tabular}

Bold text indicates statistical significance at $p<0.05$.

$\mathrm{AOR}=$ odds ratio adjusted for age, sex, past-year personal income, education, region of residence, and major depression at Wave 1.

with a lower odds of depression at Wave 2 compared to no nicotine use (OR $=0.48,95 \%$ C.I. 0.24-0.96) (data not shown). However, the effect was no longer significant when lifetime depression at Wave 1 was controlled ( $\mathrm{OR}=0.52,95 \%$ C.I. $0.26,1.05)$ (data not shown). No other odds ratios were significant in unadjusted or adjusted analyses. We also replicated these analyses using UHBs defined at Wave 2 (concurrent to measurement of discrimination): results were unchanged.

Table 2

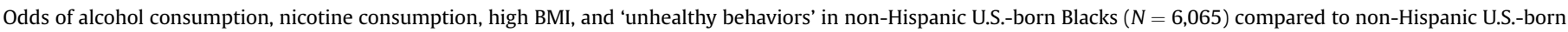
Whites $(N=19,216)$ at low, moderate, and high levels of stress.

\begin{tabular}{|c|c|c|c|c|c|c|c|c|c|}
\hline & \multicolumn{3}{|c|}{ No stressful life events $(N=7274)$} & \multicolumn{3}{|c|}{$1-2$ stressful life events $(N=11832)$} & \multicolumn{3}{|c|}{$\begin{array}{l}\text { Three or more stressful life events } \\
(N=6175)\end{array}$} \\
\hline & \multirow{2}{*}{$\begin{array}{l}\text { Blacks } \\
N=1531 \\
\end{array}$} & \multirow{2}{*}{$\begin{array}{l}\text { Whites } \\
N=5743 \\
\end{array}$} & \multirow[t]{3}{*}{ AOR (95\% C.I.) } & \multirow{2}{*}{$\begin{array}{l}\text { Blacks } \\
N=2786 \\
\end{array}$} & \multirow{2}{*}{$\begin{array}{l}\text { Whites } \\
N=9046 \\
\end{array}$} & \multirow[t]{3}{*}{ AOR (95\% C.I.) } & \multirow{2}{*}{$\begin{array}{l}\text { Blacks } \\
N=1748 \\
\end{array}$} & \multirow{2}{*}{$\frac{\text { Whites }}{N=4427}$} & \multirow[t]{3}{*}{ AOR (95\% C.I.) } \\
\hline & & & & & & & & & \\
\hline & $\%$ & $\%$ & & $\%$ & $\%$ & & $\%$ & $\%$ & \\
\hline \multicolumn{10}{|l|}{ Alcohol consumption } \\
\hline $\begin{array}{l}\text { Alcohol abuse/dependence or at } \\
\text { least weekly binge drinking }\end{array}$ & 7.58 & 8.46 & $0.55(0.39-0.79)$ & 8.59 & 10.85 & $0.57(0.45-0.72)$ & 16.49 & 21.40 & $0.50(0.40-0.63)$ \\
\hline $\begin{array}{l}\text { Non-pathological and less than } \\
\text { weekly binge drinking }\end{array}$ & 37.12 & 56.74 & $0.45(0.37-0.55)$ & 43.03 & 59.06 & $0.52(0.45-0.59)$ & 48.72 & 58.43 & $0.52(0.43-0.61)$ \\
\hline Alcohol abstention & 55.30 & 34.80 & 1.00 & 48.37 & 30.09 & 1.00 & 34.79 & 20.17 & 1.00 \\
\hline \multicolumn{10}{|l|}{ Nicotine consumption } \\
\hline Nicotine dependent & 5.31 & 7.65 & $0.54(0.39-0.74)$ & 9.12 & 12.04 & $0.56(0.46-0.69)$ & 15.36 & 26.99 & $0.35(0.28-0.42)$ \\
\hline Non-dependent nicotine use & 13.73 & 12.66 & $0.83(0.67-1.03)$ & 15.17 & 13.31 & $0.90(0.74-1.08)$ & 13.46 & 14.26 & $0.63(0.52-0.78)$ \\
\hline Nicotine abstention & 80.96 & 79.69 & 1.00 & 75.71 & 74.65 & 1.00 & 71.18 & 58.75 & 1.00 \\
\hline \multicolumn{10}{|l|}{ BMI } \\
\hline$\geq 35$ & 11.09 & 6.26 & $2.38(1.78-3.19)$ & 13.97 & 7.29 & $2.43(1.94-3.04)$ & 17.56 & 10.29 & $2.16(1.74-2.68)$ \\
\hline$>25-<35$ & 55.98 & 49.41 & $1.82(1.49-2.21)$ & 55.58 & 51.07 & $1.55(1.32-1.83)$ & 50.00 & 46.24 & $1.62(1.33-1.96)$ \\
\hline$\leq 25$ & 32.93 & 44.33 & 1.00 & 30.45 & 41.64 & 1.00 & 32.44 & 43.47 & 1.00 \\
\hline \multicolumn{10}{|l|}{ Unhealthy behavior count } \\
\hline Four or more & 6.11 & 5.57 & $0.85(0.56-1.28)$ & 8.39 & 8.75 & $0.69(0.52-0.92)$ & 15.09 & 20.86 & $0.33(0.24-0.45)$ \\
\hline One to three & 76.79 & 80.81 & $1.00(0.71-1.10)$ & 79.54 & 81.82 & $0.82(0.67-1.01)$ & 75.36 & 74.07 & $0.55(0.43-0.71)$ \\
\hline None & 17.10 & 13.61 & 1.00 & 12.07 & 9.42 & 1.00 & 9.55 & 5.13 & 1.00 \\
\hline
\end{tabular}

Bold text indicates statistical significance at $p<0.05$.

$\mathrm{AOR}=$ odds ratio adjusted for age, sex, past-year personal income, education, and region of residence. 
Table 3

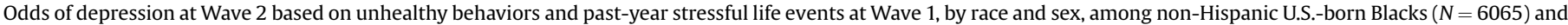
non-Hispanic U.S.-born Whites $(N=19,216)$ in the general population.

\begin{tabular}{|c|c|c|c|}
\hline & $\frac{\text { White }(N=19216)}{\operatorname{AOR}(95 \% \text { C.I. })}$ & $\frac{\operatorname{Black}(N=6065)}{\operatorname{AOR}(95 \% \text { C.I. })}$ & $\begin{array}{l}\text { Two way interaction between } \\
\text { race and unhealthy } \\
\text { behavior (F, df, p-value) }\end{array}$ \\
\hline \multicolumn{4}{|l|}{ No stressors } \\
\hline $\begin{array}{l}\text { Alcohol abuse/dependence or at } \\
\text { least weekly binge drinking }\end{array}$ & $0.92(0.54-1.55)$ & $1.85(0.47-7.23)$ & $0.49, \mathrm{df}=2,0.61$ \\
\hline Non-pathological drinking & $1.04(0.78-1.38)$ & $0.88(0.34-2.29)$ & \\
\hline Abstention from alcohol & 1.00 & 1.00 & \\
\hline Nicotine dependence & $1.79(1.20-2.65)$ & $1.58(0.50-4.99)$ & $0.19, \mathrm{df}=2,0.82$ \\
\hline Non-pathological nicotine use & $1.20(0.82-1.75)$ & $1.66(0.69-3.98)$ & \\
\hline No nicotine use & 1.00 & 1.00 & \\
\hline $\mathrm{BMI} \geq 35$ & $1.29(0.80-2.09)$ & $0.49(0.21-1.14)$ & $1.98, \mathrm{df}=2,0.15$ \\
\hline $\mathrm{BMI}>25-<35$ & $0.90(0.69-1.18)$ & $0.49(0.26-0.93)$ & \\
\hline $\mathrm{BMI} \leq 25$ & 1.00 & 1.00 & \\
\hline High unhealthy behavior count & $1.60(0.91-2.82)$ & $0.58(0.13-2.52)$ & $3.35, \mathrm{df}=2,0.04$ \\
\hline Low unhealthy behavior count & $1.39(0.97-2.01)$ & $0.42(0.18-0.96)$ & \\
\hline No unhealthy behaviors & 1.00 & 1.00 & \\
\hline \multicolumn{4}{|l|}{$1-2$ stressors } \\
\hline $\begin{array}{l}\text { Alcohol abuse/dependence or at } \\
\text { least weekly binge drinking }\end{array}$ & $1.15(0.84-1.57)$ & $0.60(0.32-1.15)$ & $1.50, \mathrm{df}=2,0.23$ \\
\hline Non-pathological drinking & $0.93(0.76-1.13)$ & $0.75(0.46-1.21)$ & \\
\hline Abstention from alcohol & 1.00 & 1.00 & \\
\hline Nicotine dependence & $1.65(1.28-2.12)$ & $1.26(0.74-2.12)$ & $0.34, \mathrm{df}=2,0.71$ \\
\hline Non-pathological nicotine use & $1.04(0.79-1.38)$ & $1.22(0.57-2.60)$ & \\
\hline No nicotine use & 1.00 & 1.00 & \\
\hline $\mathrm{BMI} \geq 35$ & $1.11(0.81-1.53)$ & $1.30(0.82-2.08)$ & $0.98, \mathrm{df}=2,0.38$ \\
\hline $\mathrm{BMI}>25-<35$ & $1.09(0.91-1.31)$ & $0.92(0.64-1.32)$ & \\
\hline $\mathrm{BMI} \leq 25$ & 1.00 & 1.00 & \\
\hline High unhealthy behavior count & $1.38(0.93-2.04)$ & $1.24(0.53-2.90)$ & $0.38, \mathrm{df}=2,0.69$ \\
\hline Low unhealthy behavior count & $1.06(0.79-1.43)$ & $1.29(0.74-2.24)$ & \\
\hline No unhealthy behaviors & 1.00 & 1.00 & \\
\hline \multicolumn{4}{|l|}{3 or more stressors } \\
\hline $\begin{array}{l}\text { Alcohol abuse/dependence or at } \\
\text { least weekly binge drinking }\end{array}$ & $1.20(0.90-1.60)$ & $1.18(0.69-2.04)$ & $0.22, \mathrm{df}=2,0.80$ \\
\hline Non-pathological drinking & $0.96(0.76-1.22)$ & $0.82(0.55-1.21)$ & \\
\hline Abstention from alcohol & 1.00 & 1.00 & \\
\hline Nicotine dependence & $1.44(1.15-1.80)$ & $0.96(0.62-1.48)$ & $1.90, \mathrm{df}=2,0.16$ \\
\hline Non-pathological nicotine use & $0.94(0.71-1.24)$ & $0.62(0.37-1.05)$ & \\
\hline No nicotine use & 1.00 & 1.00 & \\
\hline $\mathrm{BMI} \geq 35$ & $1.81(1.39-2.37)$ & $1.19(0.73-1.94)$ & $1.49, \mathrm{df}=2,0.23$ \\
\hline $\mathrm{BMI}>25-<35$ & $1.43(1.18-1.74)$ & $1.21(0.83-1.77)$ & \\
\hline $\mathrm{BMI} \leq 25$ & 1.00 & 1.00 & \\
\hline High unhealthy behavior count & $2.03(1.26-3.27)$ & $1.12(0.52-2.45)$ & $1.36 \mathrm{df}=2,0.26$ \\
\hline Low unhealthy behavior count & $1.39(0.92-2.11)$ & $1.13(0.57-2.25)$ & \\
\hline No unhealthy behaviors & 1.00 & 1.00 & \\
\hline \multicolumn{4}{|l|}{ Three-way interctions } \\
\hline \multicolumn{4}{|l|}{ Stress by race by } \\
\hline Alcohol consumption & $0.55, \mathrm{df}=12,0.87$ & & \\
\hline Nicotine consumption & $0.91, \mathrm{df}=12,0.54$ & & \\
\hline BMI & $2.11, \mathrm{df}=12,0.03$ & & \\
\hline UHB count & $1.02, \mathrm{df}=12,0.44$ & & \\
\hline
\end{tabular}

Bold text indicates statistical significance at $p<0.05$.

AOR = odds ratio adjusted for age, sex, past-year personal income, education, region of residence, and major depression at Wave 1 . 


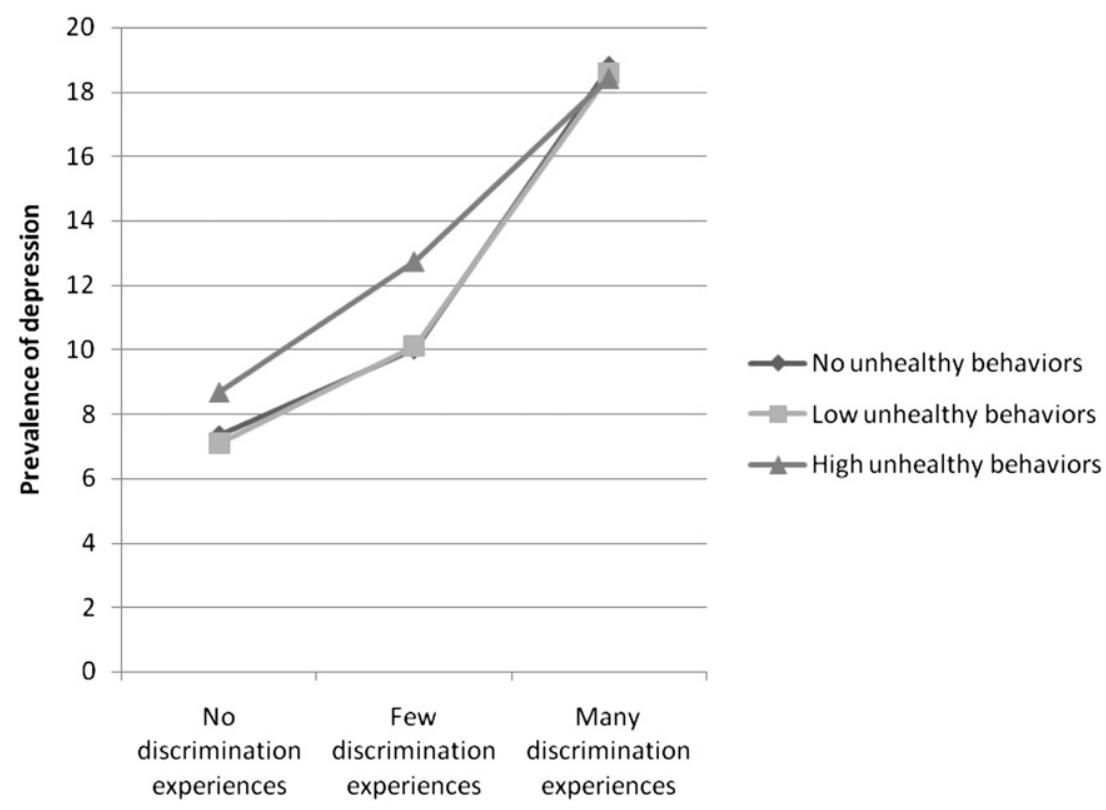

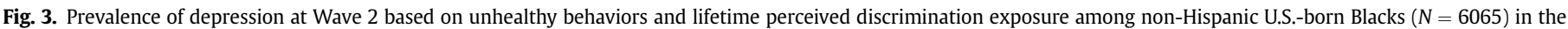
general population.

\section{Discussion}

The present study did not find support for the hypothesis that engaging in unhealthy behaviors ameliorates major depression among Blacks in the U.S. exposed to high levels of stress, or that a differential effect of UHBs on depression among Blacks compared with Whites accounts for the mental/physical health paradox. First, we showed that the results presented in Jackson et al. (2009) and Mezuk et al. (2010) do not replicate in a nationally-representative sample using model specification to account for the non-linear association between stress and depression among Blacks that we observed in these data. Next, as part of a more in-depth investigation of the hypothesis, we demonstrated that the relationship between depression and alcohol consumption, nicotine consumption, and BMI among Blacks is not statistically significant and, in fact, the direction of association between UHBs and depression is positive, not negative. Third, we documented that Blacks are less likely to engage in alcohol and nicotine consumption but have higher BMI than Whites at all levels of stress. We note, however, that an overall count of UHBs was not associated with race among those with no stressful life events. This suggests a complex patterning of unhealthy behaviors and race across stress levels that should be more comprehensively examined in these and other data in future analyses.

Finally, we showed that while race, stress, and BMI did interact significantly to predict depression in this sample, being overweight was protective against depression among Blacks only at very low levels of stress. Similarly, among those with no stressful life events, we found that low levels of UHBs were associated with less depression in Blacks but not Whites, though this result was significant among men only and a three-way interaction test was not significant. Furthermore, examination of perceived discrimination as a measure of stress in Blacks revealed no significant effects of unhealthy behaviors on depression at any exposure level. Taken together, these results indicate that engagement in unhealthy behaviors, especially at pathological levels, does not protect against depression, and that stress pathways do not operate differently in Blacks compared with Whites in the U.S. Thus, our confidence in the group-specific stress and coping hypothesis proposed by Jackson and colleagues (Jackson \& Knight, 2006; Jackson et al., 2009; Mezuk et al., 2010) is diminished.
Although UHBs may have immediate positive psychological effects via the HPA axis, the evidence presented here suggests these effects are not robust enough to prevent the clinical manifestation of major depression.

We did find evidence that some measures of unhealthy behaviors were significant predictors of depression in Whites but not Blacks. For example, at high levels of stress, Whites with high BMI, nicotine dependence, and a high unhealthy behavior count were more likely to evidence depression compared with Whites without these unhealthy behaviors, but the same predictors were not significant among Blacks. However, we caution against over-interpretation of these findings; as noted by Gelman \& Stern (2006): "The Difference Between 'Significant' and 'Not Significant' is not Itself Statistically Significant". There were no significant interactions between race and unhealthy behaviors at high levels of stress, indicating that the odds ratios across race categories were not statistically distinguishable. Further, ignoring significance levels, thirty-two of forty-eight odds ratios calculated (67\%) in the total sample were in the same direction for Whites and Blacks. Thus, the most appropriate conclusion from these data is the pathway through which unhealthy behaviors and stress impact depression does not differ in Blacks compared with Whites in the U.S., and that in general, UHBs increase the risk for depression at all levels of stress.

In the present analysis we predicted major depression during a three-year follow-up based on stressful events and UHBs assessed at baseline. While this strategy is most appropriate to establish temporality, it may overlook a key component of the hypothesis, namely, that UHBs in response to stress are active coping strategies for the suppression of immediate depressive symptoms (Benowitz, 1988; Dallman et al., 2003; Jackson \& Knight, 2006; Jackson et al., 2009; Koob et al., 1998). Thus, we may have failed to capture protective effects because we did not examine major depressive episodes concurrent with stressors and unhealthy behaviors. To explore this possibility, we re-analyzed our data using stress, UHBs and depression diagnoses all measured concurrently, at both baseline and follow-up. Neither analysis suggested different conclusions; results were generally consistent with those presented in our main analyses. Thus, we conclude that these data, analyzed multiple ways 
at multiple time points, do not provide sufficient evidence for either a protective effect of UHBs on depression, or a differential pathway through which unhealthy behaviors affect depression in Blacks compared with Whites, regardless of the exposure to stress.

These results decrease confidence in the validity of the hypothesis that group-specific stress processes explain the depression difference in Blacks and Whites, leaving open other theories to be tested. Measurement and selection bias hypotheses are unlikely to fully explain the "paradox" (Breslau et al., 2008), suggesting the need for both new theories and more direct tests of existing theories based on the premise that the lower prevalence of depression in Blacks is not artefactual. Studies suggest that Blacks develop different coping strategies when faced with life stress compared with Whites (Maton et al., 1996; Smith, 1985; Wilson, 1989), which, given the extraordinary nature and degree of stress to which Blacks are exposed starting at a young age, are hypothesized to develop over the life course. Compared with Whites, Blacks are more likely to find emotional strength and support in religious communities (Gibson \& Hendricks, 2006; Giger et al., 2008; Taylor et al., 1996), and develop racial self-esteem and strong ethnic identity (Nagel, 1994). Further, extensive research has documented the 'John Henryism' effect among Blacks in the U.S., the personality trait characterized by active coping with stressful and negative experiences and associated with worse health outcomes for Blacks at high levels of socio-economic position (James, 1994; James et al., 1987). Alternatively, the present DSM nosology may not accurately tap Black psychological responses to their unique stress exposures, and therefore DSM-IV depression as currently defined may not be the appropriate outcome to fully understand racial differences in depressive mood states (Brown, 2003; Kendrick et al., 2007). Support for this theory can be drawn from the multiple studies showing that Blacks report lower levels of well-being, higher levels of distress, and higher depressive scores when measured on nonDSM instruments (Brown, 2003; Mabry \& Kiecolt, 2005). Taken together, the results from the present study should serve as a catalyst to promote the advancement of innovative and alternative theories to explain the Black/White paradox in mental and physical health. Few studies are conducted with the primary aim of untangling this paradox, a situation that should be redressed. Such research should include rich measurement of the social and economic context, and conduct in-depth examination of the role of ethnic identity, religion, and responses to group-specific stressors, such as racial discrimination.

Several limitations should be noted. First, our measure of stressful life events is a checklist of experiences susceptible to respondent subjectivity and appraisal processes, and without regard to salience, severity, or context of experience. Substantial evidence indicates that objective measures of stressful experiences as well as information on the context of the experience is necessary to fully analyze and interpret stress in mental health research (Dohrenwend, 1998, 2006). Additionally, the stressful events experienced by Blacks in the U.S. may be more chronic and race-specific than what is captured in the scale of past-year stressors (Jones, 2000; Kreiger, 2000). We attempted to mitigate this limitation by also using a measure of perceived racial/ethnic discrimination. Further, we evaluated whether results changed if higher cut-offs of past-year stressful experiences were used to define the 'high stress' exposure group; higher cut-offs did not change the results. Thus, the conclusions from these data are limited by the available stress measure.

In conclusion, the persistent differences in health outcomes between White and Black adults remain one of the most challenging public health issues in the U.S. As theories regarding the etiology of these differences continue to develop, the mental health 'paradox' will be increasingly important to explain as part of a robust etiologic pathway. Substantive etiologic hypotheses that simultaneously explain why Blacks in the U.S. have higher rates of physical illness and lower rates of mood disorders need to be tested directly in order to resolve the 'paradox' and progress toward intervention and prevention efforts.

\section{Acknowledgments}

This research was supported in part by a fellowship from the National Institute of Mental Health (T32MH013043-36, Barnes) and a fellowship from the National Institute of Drug Abuse (F31DA026689, Keyes).

\section{References}

Baker, F. M. (2001). Diagnosing depression in African Americans. Community Mental Health Journal, 37(1), 31-38.

Benowitz, N. L. (1988). Drug therapy. Pharmacologic aspects of cigarette smoking and nicotine addition. New England Journal of Medicine, 319(20), 1318-1330.

Breslau, J., Javaras, K. N., Blacker, D., Murphy, J. M., \& Normand, S. T. (2008). Differential item functioning between ethnic groups in the epidemiological assessment of depression. Journal of Nervous and Mental Disease, 196(4), 297-306.

Breslau, J., Aguilar-Gaxiola, S., Kendler, K. S., Su, M., Williams, D., \& Kessler, R. C. (2006). Specifying race-ethnic differences in risk for psychiatric disorder in a USA national sample. Psychologie Médicale, 36(1), 57-68.

Brown, T. (2003). Critical race theory speaks to the sociology of mental health: mental health problems produced by racial stratification. Journal of Health and Social Behavior, 44(3), 292-301.

Centers for Disease Control and Prevention. (2010). http://www.cdc.gov/ healthyweight/assessing/bmi/adult_bmi/index.html.

Dallman, M. F., Pecoraro, N., Akana, S. F., la Fleur, S. E., Gomez, F., Houshyar, H., et al. (2003). Chronic stress and obesity: a new view of "comfort food". Proceedings of the National Academy of Sciences of the United States of America, 100(20), 11696-11701.

Dohrenwend, B. P. (1998). Adversity, stress, and psychopathology. New York: Oxford University Press, USA.

Dohrenwend, B. P. (2000). The role of adversity and stress in psychopathology: some evidence and its implications for theory and research. Journal of Health and Social Behavior, 41(1), 1-19.

Dohrenwend, B. P. (2006). Inventorying stressful life events as risk factors for psychopathology: toward resolution of the problem of intracategory variability. Psychological Bulletin, 132(3), 477-495.

Gelman, A., \& Stern, H. (2006). The difference between "significant" and "not significant" is not itself statistically significant. American Statistician, 60(4), $328-331$.

Geronimus, A. T. (1994). The weathering hypothesis and the health of African American women and infants: Implications for reproductive strategies and policy analysis. Power and decision: the social control of reproduction. Cambridge, MA: Harvard University Press.

Geronimus, A. T. (1996). Black/White differences in the relationship of maternal age to brithweight: a population based test of the weathering hypothesis. Social Science E Medicine, 42(4), 589-597.

Gibson, L. M., \& Hendricks, C. S. (2006). Integrative review of spirituality in African American breast cancer survivors. Association of Black Nursing Faculty, 17(2), 67-72.

Giger, J. N., Appel, S. J., Davidhizar, R., \& Davis, C. (2008). Church and spirituality in the lives of the African American community. Journal of Transcultural Nursing, 19 (4), 375-383.

Grant, B. F., Hasin, D. S., Chou, S. P., Stinson, F. S., \& Dawson, D. A. (2004). Nicotine dependence and psychiatric disorders in the United States: results from the national epidemiologic survey on alcohol and related conditions. Archives of General Psychiatry, 61(11), 1107-1115.

Grant, B. F., Goldstein, R. B., Chou, S. P., Huang, B., Stinson, F. S., Dawson, D. A., et al. (2009). Sociodemographic and psychopathologic predictors of first incidence of DSM-IV substance use, mood and anxiety disorders: results from the Wave 2 National epidemiologic survey on alcohol and related conditions. Molecular Psychiatry, 14(11), 1051-1066.

Haimoto, H., Iwata, M., Wakai, K., \& Umegaki, H. (2008). Long-term effects of a diet loosely restricting carbohydrates on HbA1c levels, BMI and tapering of sulfonylureas in type 2 diabetes: a 2-year follow-up study. Diabetes Research and Clinical Practice, 79(2), 350-356.

Hasin, D. S., Stinson, F. S., Ogburn, E., \& Grant, B. F. (2007). Prevalence, correlates, disability, and comorbidity of DSM-IV alcohol abuse and dependence in the United States: results from the National Epidemiologic Survey on alcohol and related conditions. Archives of General Psychiatry, 64(7), 830-842.

Hasin, D. S., Goodwin, R. D., Stinson, F. S., \& Grant, B. F. (2005). Epidemiology of major depressive disorder: results from the National Epidemiologic Survey on alcoholism and related conditions. Archives of General Psychiatry, 62(10), 1097-1106.

Heckler, M. M. (1985). "Task force on Black and minority health." Report of the secretary's task force on Black and minority health. Washington, DC: National Academy Press. 
Hetherington, M. M., \& Cecil, J. E. (2010). Gene-environment interactions in obesity. Forum of Nutrition, 63, 195-203.

Jackson, J. S., Knight, K. M., \& Rafferty, J. A. (2009). Race and unhealthy behaviors: chronic stress, the HPA axis, and physical and mental health disparities over the life course. American Journal of Public Health.

Jackson, J. S., \& Knight, K. M. (2006). Race and self-regulatory behaviors: the role of the stress response and HPA axis in physical and mental health disparities. In L. L. Carstensen, \& K. W. Schaie (Eds.), Social structure, aging, and self-regulation in the elderly. New York, NY: Springer.

James, S. A. (1994). John Henryism and the health of African Americans. Culture of Medicine and Psychiatry, 18, 163-182.

James, S. A., Strogatz, D. S., Wing, S. B., \& Ramsey, D. L. (1987). Socioeconomic status, John Henryism, and hypertension in Blacks and Whites. American Journal of Epidemiology, 126(4), 664-673.

Jones, C. P. (2000). Levels of racism: a theoretic framework and a gardener's tale American Journal of Public Health, 90(8), 1212-1215.

Kendrick, L., Anderson, N. L. R., \& Moore, B. (2007). Perceptions of depression among young African American men. Family and Community Health, 30(1) 63-73.

Kent, L. M., \& Worsley, A. (2009). Trends in BMI, diet and lifestyle between 1976 and 2005 in North Sydney. Asia Pacific Journal of Clinical Nutrition, 18(3), 453-461.

Kessler, R. C., McGonagle, K. A., Zhao, S., Nelson, C. B., Hughes, M., Eshleman, S., et al. (1994). Lifetime and 12-month prevalence of DSM-III-R psychiatric disorders in the United States. Results from the national comorbidity survey. Archives of General Psychiatry, 51(1), 8-19.

Kessler, R. C., Mickelson, K. D., \& Williams, D. R. (1999). The prevalence, distribution, and mental health correlates of perceived discrimination in the United States. Journal of Health and Social Behavior, 40(3), 208-230.

Kessler, R. C., Crum, R. M., Warner, L. A., Nelson, C. B., Schulenberg, J., \& Anthony, J. C. (1997). Lifetime co-occurrence of DSM-III-R alcohol abuse and dependence with other psychiatric disorders in the National Comorbidity Survey. Archives of General Psychiatry, 54, 313-321.

Klatsky, A. L. (2009). Alcohol and cardiovascular diseases. Expert Review of Cardiovascular Therapy, 7(5), 499-506.

Kleinman, A. (2004). Culture and depression. New England Journal of Medicine, 351(10), 951-953.

Koob, G. F., Roberts, A. J., Schulteis, G., Parsons, L. H., Heyser, C. J., Hyytiä, P., et al. (1998). Neurocircuitry targets in ethanol reward and dependence. Alcoholism: Clinical and Experimental Research, 22(1), 3-9.

Kreiger, N. (2000). Discrimination and health. Social epidemiology. New York: Oxford University Press. 36-75.

Krieger, N. (1990). Racial and gender discrimination: risk factors for high blood pressure? Social Science \& Medicine, 30(12), 1273-1281.

Krieger, N., Smith, K., Naishadham, D., Hartman, C., \& Barbeau, E. M. (2005) Experiences of discrimination: validity and reliability of a self-report measure for population health research on racism and health. Social Science \& Medicine, 61(7), 1576-1596.

Krieger, N., \& Sidney, S. (1996). Racial discrimination and blood pressure: the CARDIA Study of young Black and White adults. American Journal of Public Health, 86(10), 1370-1378.

Leonard, B. (2000). Stress, depression, and the activation of the immune system. World Journal of Biological Psychiatry, 1(1), 17-25.

Mabry, J. B., \& Kiecolt, K. J. (2005). Anger in Black and White: race, alienation, and anger. Journal of Health and Social Behavior, 46(1), 85-101.

Massey, D. S. (1985). Residential segregation and neighborhood conditions in U.S. metropolitan areas. In N. Smesler, W. J. Wilson, \& F. Mitchell (Eds.), America becoming racial: Trends and their consequences (pp. 391-434). Wasington, D.C. National Academy Press.

Massey, D. S. (2004). Segregation and stratification: a biosocial perspective. DuBois Reviews of Social Science, 1, 7-25

Maton, K. I., Teti, D. M., Corns, K. M., Vieira-Baker, C. C., Lavine, J. R., Gouze, K. R. et al. (1996). Cultural specificity of support sources, correlates and contexts: three studies of African-American and Caucasian youth. American Journal of Community Psychology, 24(4), 551-587.

McCord, C., \& Freeman, H. P. (1990). Excess mortality in Harlem. New England Journal of Medicine, 322(3), 173-177.

McEwen, B. S. (2000). Allostasis and allostatic load: implications for neuropsychopharmacology. Neuropsychopharmacology, 22(2), 108-124.

McEwen, B. S. (2003). Mood disordesr and allostatic load. Biological Psychiatry, 54(3), 200-207.
McEwen, B. S. (2004). Protection and damage from acute and chronic stress: allostasis and allostatic overload and relevance to the pathophysiology of psychiatric disorders. Annals of the New York Academy of Sciences, 1032, 1-7.

Mezuk, B., Rafferty, J. A., Kershaw, K. N., Hudson, D., Abdou, C. M., Lee, H., et al. (2010). Reconsidering the role of social disadvantage in physical and mental health: stressful life events, health behaviors, race, and depression. American Journal of Epidemiology, 172(11), 1238-1249.

Nagel, J. (1994). Constructing ethnicity: creating and recreating ethnic identity and culture. Social Problems, 41(1).

Neighbors, H. W., Trierweiler, S. J., Munday, C., Thompson, E. E., Jackson, J. S., Binion, V. J., et al. (1999). Psychiatric diagnosis of African Americans: diagnostic divergence in clinician-structured and semistructured interviewing conditions. Journal of the National Medical Association, 91(11), 601-612.

Neighbors, H. W., Trierweiler, S. J., Ford, B. C., \& Muroff, J. R. (2003). Racial differences in DSM diagnosis using a semi-structured instrument: the importance of clinical judgment in the diagnosis of African Americans. Journal of Health and Social Behavior, 44(3), 237-256.

Petit, B., \& Western, B. (2004). Mass imprisonment and the life course: race and class inequality in U.S. incarceration. American Sociological Review, 69, 601-612.

Regier, D. A., Farmer, M. E., Rae, D. S., Locke, B. Z., Keith, S. J., Judd, L. L., et al. (1990). Comorbidity of mental disorders with alcohol and other drug abuse: results from the Epidemiologic Catchment Area (ECA) study. JAMA, 264(19), 2511-2518.

Rogler, L. H. (1999). Methodological sources of cultural insensitivity in mental health research. American Psychologist, 54(6), 424-433.

Rothman, K. J. (2008). BMI-related errors in the measurement of obesity. International Journal of Obesity (London), 32(Suppl. 3), S56-S59.

Ruan, W. J., Goldstein, R. B., Chou, S. P., Smith, S. M., Saha, T. D., Pickering, R. P., et al. (2008). The alcohol use disorder and associated disabilities interview schedule-IV (AUDADIS-IV): reliability of new psychiatric diagnostic modules and risk factors in a general population sample. Drug and Alcohol Dependence, 92(1-3), 27-36.

Saha, T. D., Chou, S. P., \& Grant, B. F. (2006). Toward an alcohol use disorder continuum using item response theory: results from the National Epidemiologic Survey on alcohol and related conditions. Psychological Medicine, 36(7), 931-941.

Saha, T. D., Compton, W. M., Pulay, A. J., Stinson, F. S., Ruan, W. J., \& Grant, B. F. (2010). Dimensionality of DSM-IV nicotine dependence in a national sample: an item response theory application. Drug and Alcohol Dependence, 108(1-2), 21-28.

Smith, E. (1985). Ethnic minorities: life stress, social support, and mental health issues. The Counseling Psychologist, 13, 537-579.

Stansfeld, S. A. (2005). Social support and social cohesion. In M. G. Marmot, \& R. G. Wilkinson (Eds.), Social determinants of health. New York: Oxford University Press.

Strakowski, S. M., Keck, P. E., Jr., Arnold, L. M., Collins, J., Wilson, R. M., Fleck, D. E., et al. (2003). Ethnicity and diagnosis in patients with affective disorders. Journal of Clinical Psychiatry, 64(7), 747-754.

Taylor, R. J., Chatters, L. M., Jayakody, R., \& Levin, J. S. (1996). Black and White differences in religious participation: a multi-sample comparison. Journal for the Scientific Study of Religion, 35, 403-410.

Teplin, L. A. (1990). The prevalence of severe mental disorder among male urban jail detainees: comparison with the Epidemiologic Catchment Area Program. American Journal of Public Health, 80(6), 663-669.

Teplin, L. A., Abram, K. M., \& McClelland, G. M. (1996). Prevalence of psychiatric disorders among incarcerated women. I. Pretrial jail detainees. Archives of General Psychiatry, 53(6), 505-512.

Williams, D. R. (2001). Racial variations in adult health status: patterns, paradoxes, and prospects. In N. J. Smelser, W. J. Wilson, \& F. Mitchell (Eds.), America becoming: Racial trends and their consequences. Washington, D.C: National Academy Press.

Williams, D. R., González, H. M., Neighbors, H., Nesse, R., Abelson, J. M., Sweetman, J., et al (2007). Prevalence and distribution of major depressive disorder in African Americans, Caribbean Blacks, and non-Hispanic Whites: results from the National Survey of American Life. Archives of General Psychiatry, 64(3), 305-315.

Williams, D. R., \& Jackson, P. B. (2005). Social sources of racial disparities in health. Health Affairs (Millwood), 24(2), 325-334.

Williams, D. R., \& Williams-Morris, R. (2000). Racism and mental health: the African American experience. Ethnicity \& Health, 5(3-4), 243-268.

Wilson, M. N. (1989). Child development in the context of the Black extended family. American Psychologist, 44, 380-383. 